\title{
Correction to: The Semantic Web: ESWC 2021 Satellite Events
}

\author{
Ruben Verborgh (D), Anastasia Dimou (D), Aidan Hogan (D), \\ Claudia d'Amato (D), Ilaria Tiddi (D), Arne Bröring (D), Simon Mayer (D), \\ Femke Ongenae (iD), Riccardo Tommasini (iD, and Mehwish Alam (iD
}

\section{Correction to: \\ R. Verborgh et al. (Eds.): The Semantic Web: ESWC 2021 \\ Satellite Events, LNCS 12739, https://doi.org/10.1007/978-3-030-80418-3}

The name of one of the volume editors, Simon Mayer, was erroneously misspelt in an earlier version of the cover and inside cover of this volume. This has now been corrected. 